\title{
INVESTIGATIONS ON RADIOACTIVE SUBSTANCES RELEASED FROM THE FUKUSHIMA DAIICHI NUCLEAR POWER PLANT
}

\author{
KATSUHIKO YAMAGUCHI and RADIATION SURVEY TEAM OF FUKUSHIMA UNIV.
}

\author{
Symbiotic Systems Science, Fukushima University, Fukushima, Japan
}

(Received October 31, 2011, accepted December 19, 2011)

\begin{abstract}
The Great East Japan Earthquake on March 11th, 2011, severely damaged the Fukushima Daiichi Nuclear Power Plant resulting in the diffusion of many radioactive substances throughout Fukushima prefecture. To examine these substances, we have carried out investigations for several months since immediately after the accident. We revealed that environmental high-level radiation spread northwesterly from the nuclear plant and several areas in Nakadori, the region located in the central part of the prefecture between Hamadori (east part of the prefecture) and Aizu-chihou (west part), was contaminated with mid-level radiation. We also analyzed radionuclides in soil and estimated future radiation levels.

The importance of topsoil removal for decontamination has become an obvious countermeasure since many radioactive substances have settled on the surface. In addition, we investigated residential areas and their surroundings to find where high-level doses were likely to be detected for lowering the risk of exposure among residents.

When little information was available, the investigations were implemented and the results contributed to both administrative policies and civil life.
\end{abstract}

\section{INTRODUCTION}

On March 11th, 2011, the accident crippling the Fukushima Daiichi Nuclear Power Plant (F1), caused by the Great East Japan Earthquake, led to the scattering of many radioactive substances. Soon after the accident, information on the actual measurement of diffusion was insufficient and only partial simulation by SPEEDI was shown to the public. The situation urged us to set up a radiation survey team in Fukushima University and to carry out several investigations into the actual conditions.

We first drew up a radioactive contamination distribution map with the measured values mainly for northern Fukushima Prefecture to grasp the actual situation. We also performed a quantitative evaluation of radionuclides in topsoil and estimated future radiation doses, and further investigated the depth distribution of radionuclides in soil to obtain information on diffusion.

Additionally, we compared several commercial radiation meters and also verified whether radiation substances were carried by traffic, in order to provide information regarding civil life. The obtaining of objective facts through actual investigations and informing the local community are considered a very important role of which a university within the region has to play, especially during a time when there is a lack of information provided.

\section{RADIATION DISTRIBUTION IN FUKUSHIMA PREFECTURE}

Residents living within $2 \mathrm{~km}$ of the Fukushima Nuclear Power Plant were ordered to evacuate immediately after the accident, and the evacuation zone was later extended to a $20 \mathrm{~km}$ radius. At the end of March, the evacuation zone was still made on the basis of a concentric circle extending from the plant. We therefore felt the need to investigate the actual distribution of radioactive substances.

In order to produce a regional radiation distribution map with the measured results, all measurements had to be made under the same environmen-

山口克彦, Radiation Survey Team Of Fukushima Univ.

Corresponding author : Katsuhiko Yamaguchi E-mail address : yama@sss.fukushima-u.ac.jp

http://www.jstage.jst.go.jp/browse/fms http://fmu.ac.jp/home/lib/F-igaku/ 


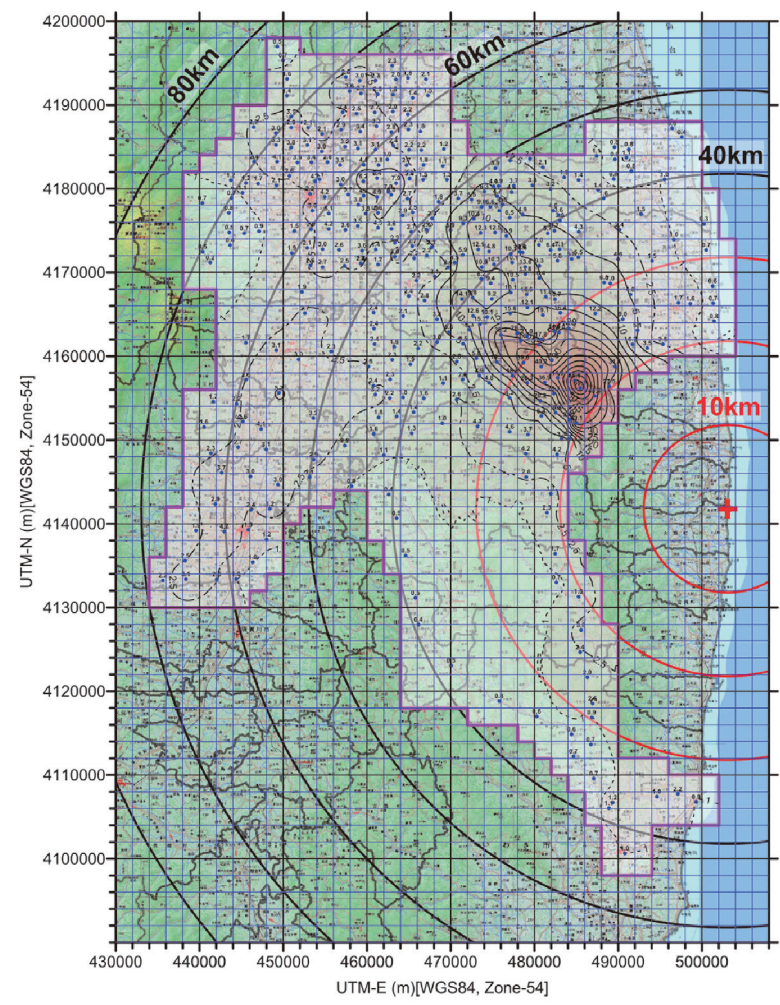

Fig. 1. Radiation map of the northern part of Fukushima Prefecture.

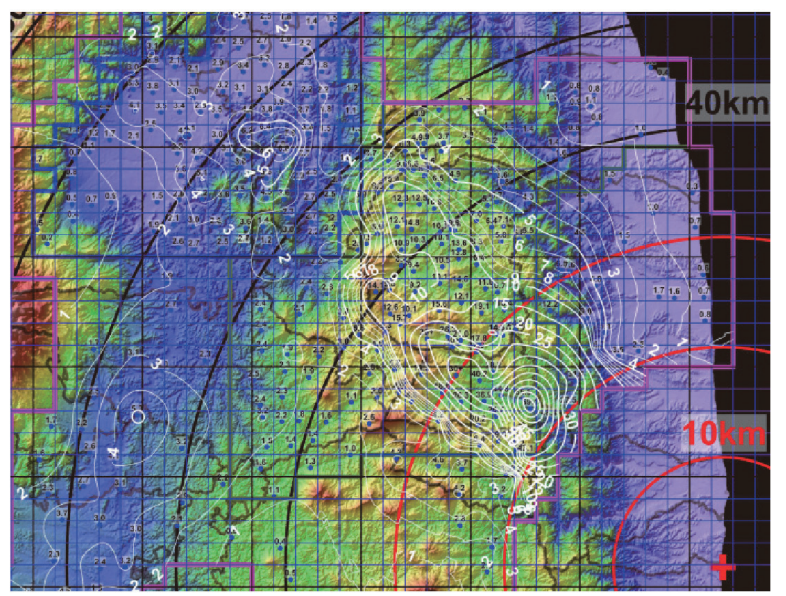

Fig. 2. Relationship between the distribution of radiation and the geography.

tal conditions, independent of several measurements made by the Ministry of Education, Culture, Sports, Science and Technology. We marked a map with $2 \mathrm{~km} \times 2 \mathrm{~km}$ grids using the Universal Transverse Mercator (UTM) coordinates (the advantage of using mesh is that it can be divided into equal squares) and confirmed the coordinates of measuring points using GPS. All measurements made for air radiation doses were taken $1 \mathrm{~m}$ above asphalt road surfaces as deposit of radioactive substances may vary in ordinal

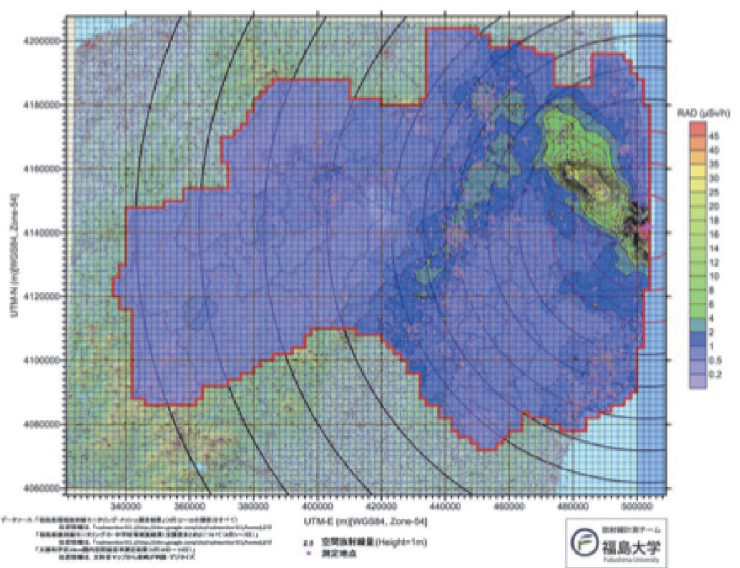

Fig. 3. Radiation map of Fukushima Prefecture.

soil affecting consistency of measurement. We used the NaI scintillation survey meter (ALOCATCS-171B) to detect $\gamma$-rays and the time constant of integration was set to 30 seconds. After the value was stabilized, the measurement was made every 30 seconds five times in succession and the mean values were taken. The measurements were made between March 25th to March 31st, 2011, and the obtained data was adjusted with the data as on March 30th. A map with isoplethic curves was made as shown in Fig. 1.

Fig. 1 clearly shows the directional dependency of radiation levels. High-level radiation distribution is seen in Namie-machi and Iitate-mura, which are located in the northwest. Nakadori, the region where Fukushima city and Koriyama city are located and where the Tohoku Shinkansen runs, is also contaminated by mid-level radiation. The geographical features of the region affected radiation distribution along with wind direction, at the time of radioactive release.

Fig. 2 is a topographic map of an enlarged view of the area northwest of the nuclear plant and contains isoplethic curves that show radiation levels. The brown-colored areas indicate high altitude and the isoplethic curves lie along the range of the Abukuma Mountains. As the radiation level was far lower at the opposite side of the mountains, they possibly to a certain extent prevented radiation from diffusing past the mountainous region.

Fig. 3 is a distribution map of radiation levels of the whole Fukushima Prefecture made by adding the investigation data taken at various points by the Fukushima prefectural government after April. In this map, the mid-level radiation areas in Nakadori are seen as predicted in Fig. 1 . At the same time, Fig. 3 clearly indicates that radiation contamination 


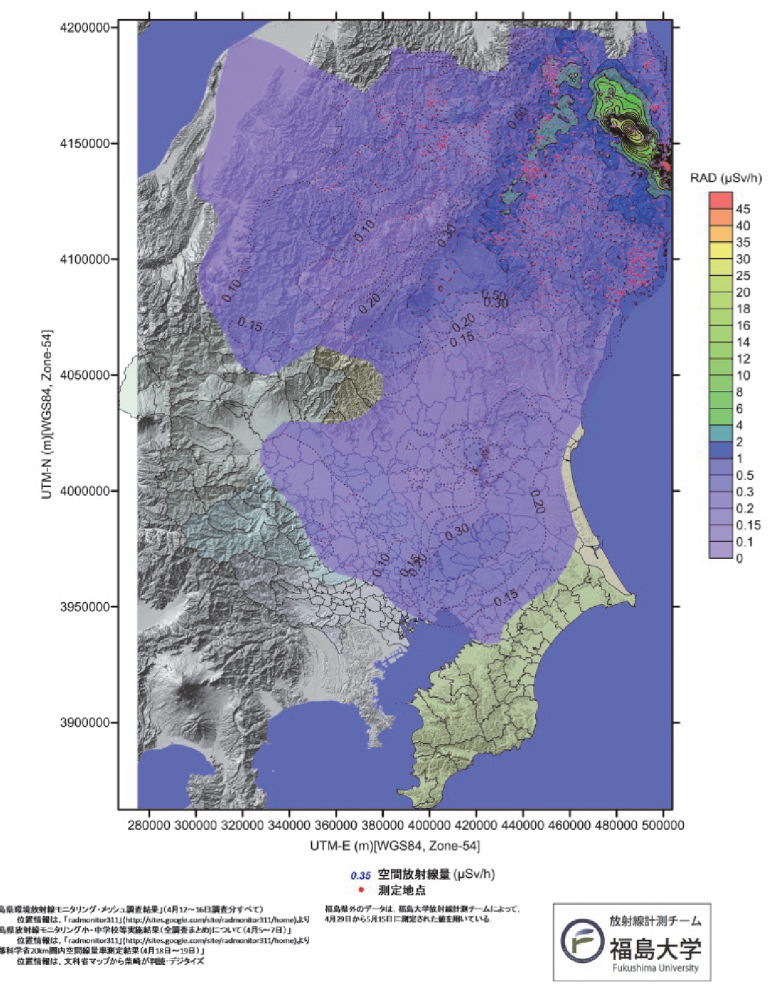

Fig. 4. Radiation map of East Japan.

further extended to other prefectures.

Radioactive substances have been thought to flow into Nakadori via two routes. One route is Namie-machi-> Iitate-mura- $>$ Fukushima city-> Koriyama city. The other is Iwaki city-> Northern Kanto->Shirakawa city-> Koriyama city -> Fukushima city. To verify the main route, we expanded our investigation to the north part of Northern Kanto.

Fig. 4 shows the results of the investigation. We can speculate that the diffusion may have mainly taken the first route since the mid-level radiation distribution in Nakadori did not connect to the radiation distribution that moved south along the Pacific coast.

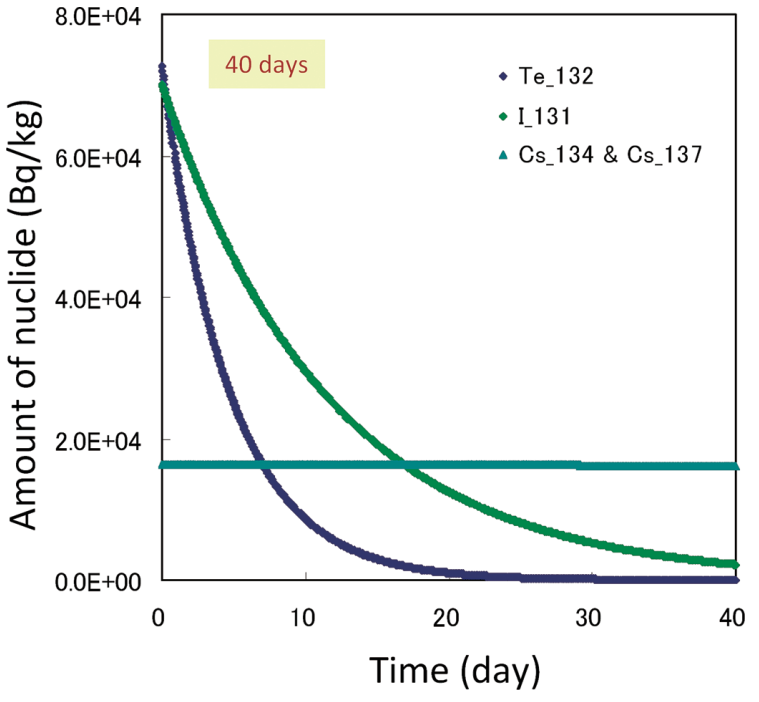

Fig. 5. Calculation of the transition of nuclide.

\section{ANALYSIS OF RADIONUCLIDES IN SOIL}

We collected soil samples from various parts in Fukushima Prefecture and identified the radioactive substances contained within the soil using the Ge detector (produced by Canberra, GC4020). The analysis results indicate that the ratio of the nuclides was similar among the samples, though the total amount of nuclides varied depending on the region. As an example, the analysis result of the soil taken from Fukushima University is shown in Table 1. The sample soil was collected on March 22nd and analyzed by the Ge detector on April 8th. The radiation doses as of March 15th and March 22nd were estimated based on the half-life of each nuclide. At the time when the analysis was done on April 8th, Te and I, of which half-lives are short, were still detectable. Almost the same amount of Cs134 and Cs137 also existed.

Based on the results, we calculated the transition of each nuclide and drew up Fig. 5 with March 15th as the base point. The radiation that Te and I emit decreased to an ignorable level at around 40 days whereas that of Cs134 and Cs137 hardly changed during that period, as their half-lives are

Table 1. Radioaciive muclide in soil

\begin{tabular}{cccccc}
\hline muclide & half life & kerma factor & Rneasurement (4/8) & $\begin{array}{c}\text { amount of muclide }(\mathrm{Bq} / \mathrm{kg}) \\
\text { estimated }(3 / 23)\end{array}$ & esliiuaLcd (3/15) \\
\hline Te-132 & $3.204 \mathrm{~d}$ & 0.032 & $4.3 \mathrm{E}+02$ & $1.4 \mathrm{E}+04$ & $7.3 \mathrm{E}+04$ \\
$\mathrm{I}-132$ & $2.295 \mathrm{~h}$ & 0.300 & & $3.6 \mathrm{E}+04$ & $7.0 \mathrm{E}+04$ \\
$\mathrm{I}-131$ & $8.020 \mathrm{~d}$ & 0.055 & $8.8 \mathrm{E}+03$ & $8.2 \mathrm{E}+03$ & $8.2 \mathrm{E}+03$ \\
Cs-134 & $2.065 \mathrm{y}$ & 0.211 & $8.1 \mathrm{E}+03$ & $8.2 \mathrm{E}+03$ & $8.2 \mathrm{E}+03$ \\
Cs-137 & $30.167 \mathrm{y}$ & 0.078 & $8.2 \mathrm{E}+03$ & & \\
\hline
\end{tabular}




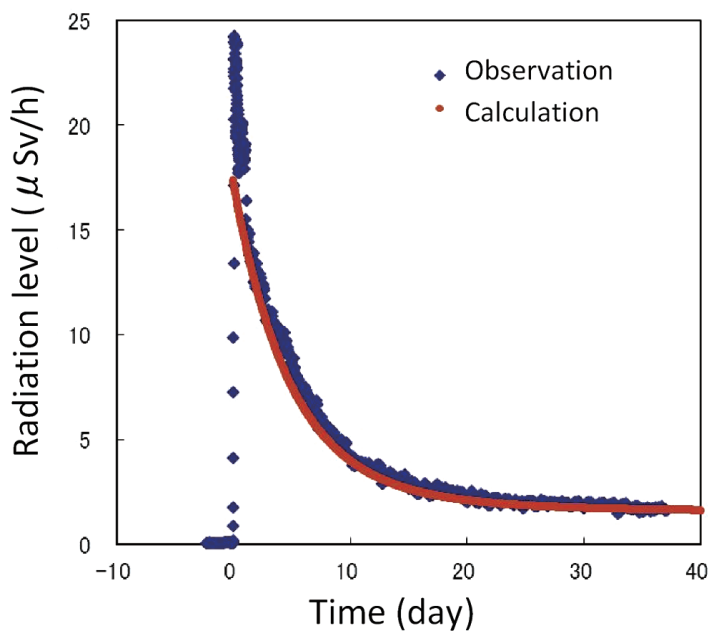

Fig. 6. Chronological changes in the total emission in Fukushima city (Blue dots; observation, Red line; calculation).

approximately two years and 30 years, respectively.

Fig. 6 shows the chronological changes in the total emission, which were carefully calculated as radiation doses differ depending on nuclide. The changes correspond well with the transition of the environmental doses in Fukushima city, which were measured by the city on March 15th. This suggests that future environmental doses may be predictable. Therefore, setting March 15th as the start point, we calculated the cumulated doses and estimated the transition of environmental radiation doses for the next five years. As the result shown in Fig. 7, the state of $1 \mu \mathrm{Sv} / \mathrm{h}$ may last for about one year and the value will decrease to $0.5 \mu \mathrm{Sv} / \mathrm{h}$ five years later. However, in reality, the environmental

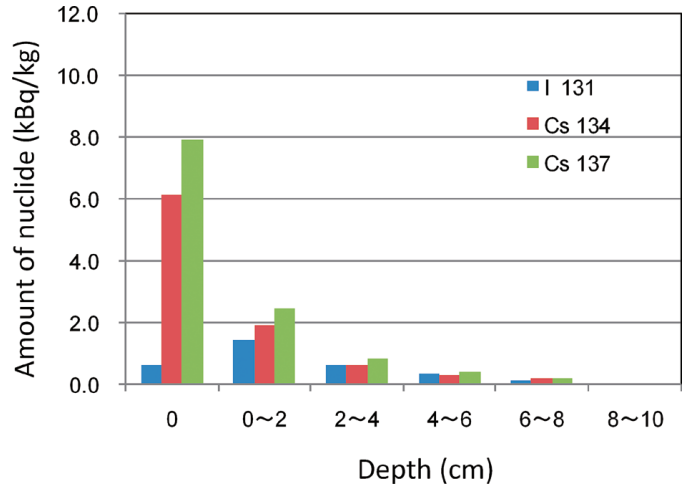

Fig. 8. Depth distribution of each radioactive nuclides in soil around Fukushima University.

radiation doses may lower faster, due to radioactive substances being washed away by rainwater. Fig. 7 also shows the transition of cumulated doses measured by a meter placed outside, which are therefore different from that of actual life. The cumulated doses will in 5 years be approximately $40 \mathrm{mSv}$.

By sampling soil of different depths, we investigated the state of radioactive substances within the soil. Fig. 8 shows the results of nuclide identification and doses measured by the Ge detector. Many of the radioactive substances remained on the topsoil and were scarcely seen deeper than $5 \mathrm{~cm}$. The depth distribution is assumed to be dependent on the characteristics of the soil, such as in playgrounds or farmlands. The results indicate the importance of immediate removal of topsoil before the substances spread to other places.

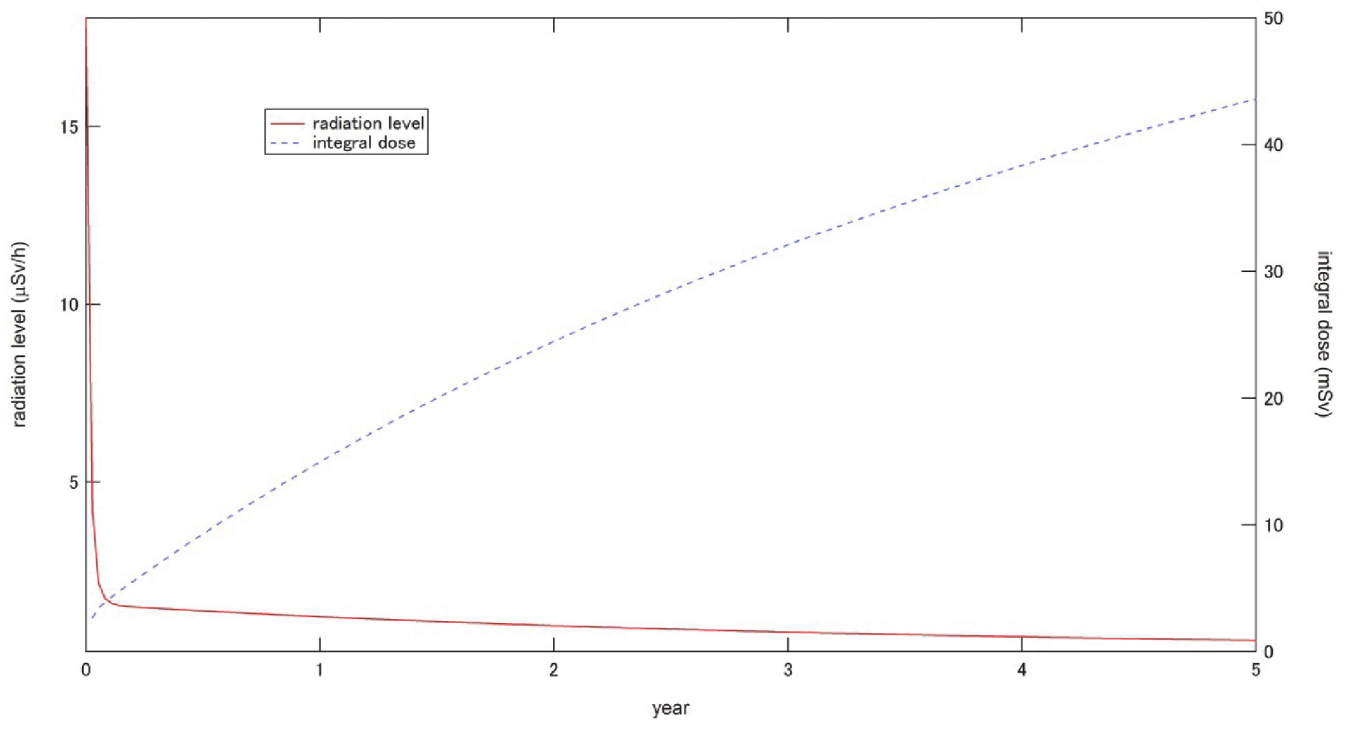

Fig. 7. Calculations of radiation level and integral dose in Fukushima City. 


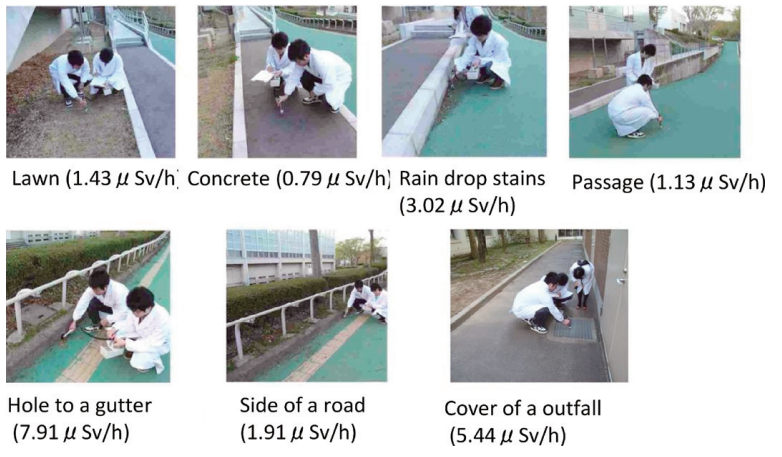

Fig. 9. Radiation levels of specified points in Fukushima University (values inside the brackets show the radiation level in units of $\mu \mathrm{Sv} / \mathrm{h}$ ).

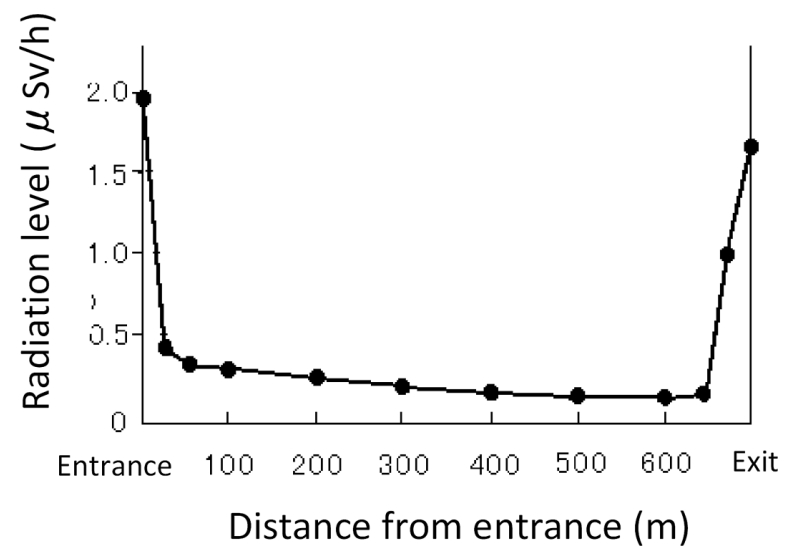

Fig. 10. Distribution of radiation level in a tunnel of about $800 \mathrm{~m}$ in length in Fukushima City.

\section{LOCALIZED DIFFUSION OF RADIOACTIVE SUBSTANCES}

I described the diffusion of radioactive substances and variation in diffusion in Section two. This variation was also seen in the localized diffusion of the substances. In order to keep the exposure as low as possible, the importance of this information must be taken into account for everyday life.

Basically, places where radioactive substances initially stayed corresponded to the places where rainwater sits. The radiation level was low in places sheltered by roof, as there had been no contact with rainwater. The level was also low at the raised center of asphalt roads as rainwater drains easily towards the sides. On the other hand, the radiation level was high at places where rainwater collected, like in street gutters. The level remained high even after the water evaporated.

Fig. 9 shows the radiation levels of specified points in Fukushima University. Each point was located in the square of which the total length of the sides was about $30 \mathrm{~m}$. Each measurement was made $5 \mathrm{~cm}$ above the surface using the NaI scintillation survey meter (ALOCA-TCS-171B) to detect $\gamma$-rays. The results indicate heavy dependence of radiation levels on the flow of rainwater as mentioned above. Even when the distance between two points was quite similar, the levels significantly differed.

Fig. 10 shows another measurement result taken at the Shinobuyama tunnel, which is located on Route 13 running through Fukushima city. At the entrance of the tunnel, the radiation level was approximately $2 \mu \mathrm{Sv} / \mathrm{h}$, however, the level rapidly decreased as we approached the center of the tunnel. This result indicates that the radiation level was low in the area unaffected by rainfall. Moreover, it clearly suggests that the flow of the traffic was not the main cause of the spread of radioactive substances. After the nuclear accident occurred, there were rumors attributing automobiles to the diffusion of radioactive substances, however, the result has proved that the rumors were unfounded.

\section{CHARACTERISTICS OF RADIATION METERS}

As time has passed since the accident, residents have voluntarily purchased radiation meters and started measuring radiation levels around their vicinities. These kinds of activities are probably essential since municipal organizations alone cannot respond to all measurement requests. However,

Table 2. Specifications of the radiation meter

\begin{tabular}{lcccc}
\hline \multicolumn{1}{c}{ Product name } & TCS-171B (ALOCA) & Hakaru-kun & DoseRAE2 & Dp802i \\
\hline Sensor type & NaI(Tl) scintillation & CsI (Tl) scintillation & CsI(Tl) scintillation & GM tube \\
Range & Back ground $\sim 30 \mu \mathrm{Sv} / \mathrm{h}$ & $0.001 \sim 9.999 \mu \mathrm{Sv} / \mathrm{h}$ & $0.01 \mu \mathrm{Sv} / \mathrm{h} \sim 10 \mathrm{~Sv} / \mathrm{h}$ & $0.01 \mu \mathrm{Sv} / \mathrm{h} \sim 150 \mathrm{mSv} / \mathrm{h}$ \\
Error bar & & $10 \%$ & $30 \%$ & $<10 \%$ \\
Energy Response & $50 \mathrm{keV} \sim 3 \mathrm{MeV}$ & $150 \mathrm{keV} \sim 3 \mathrm{MeV}$ & $20 \mathrm{keV} \sim 6 \mathrm{MeV}$ & $40 \mathrm{keV} \sim 1.5 \mathrm{MeV}$ \\
Radiation type & $\gamma-$ ray & $\gamma-$ ray & $\mathrm{X}$-ray, $\gamma$-ray & $\gamma$-ray, $\beta$-ray \\
Time constant & $3,10,30 \mathrm{~s}$ & $60 \mathrm{~s}$ & & \\
Sensitivity & $45,000 \mathrm{cpm} / \mu \mathrm{Sv} / \mathrm{h}$ & $1,000 \mathrm{cpm} / \mu \mathrm{Sv} / \mathrm{h}$ & & \\
\hline
\end{tabular}



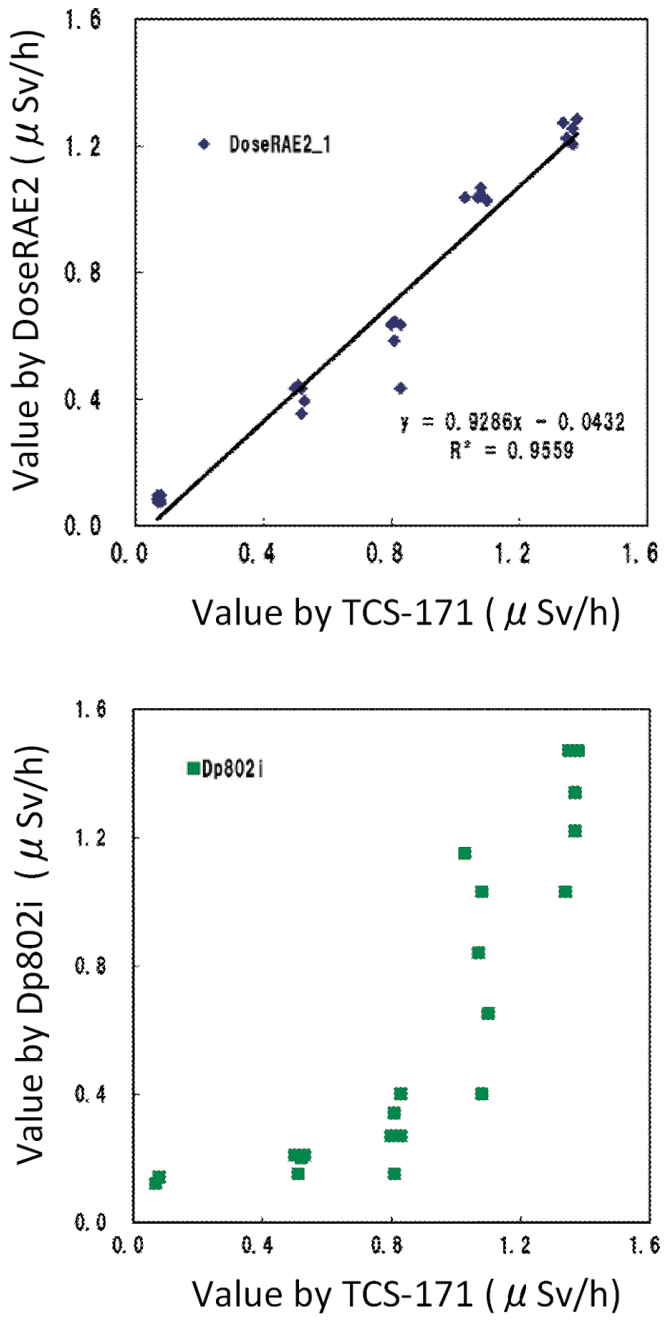

Fig. 11. Correlation of doses measured by DoseRAE2 with the CsI (Tl) scintillation, Dp802i with GM tube, and TCS-171B under the same condition.

the accuracy of some radiation meters needs to be considered.

Table 2 shows specifications of the radiation meter, ALOCA-TCS-171B, which we used in the present study, and that of other meters. Radiation meters are categorized into several types such as the NaI (Tl) scintillation used in ALOCA-TCS171B, CsI (T1) scintillation, or the Geiger-Müller (GM) tube. Many people use the CsI (T1) scintillation or GM tubes as some of these meters cost less than 100,000 yen, whereas the more expensive NaI (Tl) scintillation costs approximately 500,000 yen. Among those meters, however, there is a difference in precision. For example, for $\gamma$-ray sensitivity, TCS-171B measures $45,000 \mathrm{cpm}$ per $1 \mu \mathrm{Sv} / \mathrm{h}$ while Hakarukun (CsI (T1) scintillation), which is commonly used in schools, measures only about $1,000 \mathrm{cpm}$. This causes measurement errors particularly when measuring the doses in low-level radiation areas. However, meters such as Hakarukun can be properly used should the linearity of detection sensitivity be retained and the correlation of the absolute values of radiation levels be confirmed using a meter like the TCS-171B. The problem is that there are commercial radiation meters, which do not have linearity. Such meters, especially ones with GM tubes have been widely sold. These are inexpensive and have simple structures but are problematic. Fig. 11 shows the correlation of doses measured by DoseRAE2 with the CsI (Tl) scintillation, Dp802i with GM tube, and TCS-171B under the same condition. DoseRAE2 seems the appropriate choice for measuring doses as it correlates well and relates linearly with TCS171B. In comparison, Dp802i did not show linearity and had variation in measured values and therefore using data measured by such meters with GM tubes is assumed as being very risky.

The measurement of radiation doses will likely remain as an important activity of citizens in the future. Therefore, it is necessary for people to be aware of precision and characteristics of their meters before making such measurement. This may require people's meters to be correlated with a meter that is reliable for calibration. Establishing a system to meet such needs may soon need to be considered.

\section{CONCLUSION}

Until the end of July 2011, the previously described investigations were implemented. Since the measurement data publicized by municipal governments or other organizations was insufficient, especially during March and April, we struggled to grasp the actual conditions through our investigations. In the earliest stage of our investigations we gave effects on policies that the municipal governments took on later. The investigations we carried out were considered to be obligations of a university located in Fukushima Prefecture. Many organizations have taken investigations into their own hands lately revealing various aspects of the impact caused by the nuclear accident. As a local research institute, we believe that our role is to continue investigations with community-based perspectives. 